\title{
NOURISH OUR WORLD [NOW]. \\ CREATING DEMAND FOR NUTRITIOUS \\ DIETS
}

25-26 February 2019, Amsterdam, The Netherlands

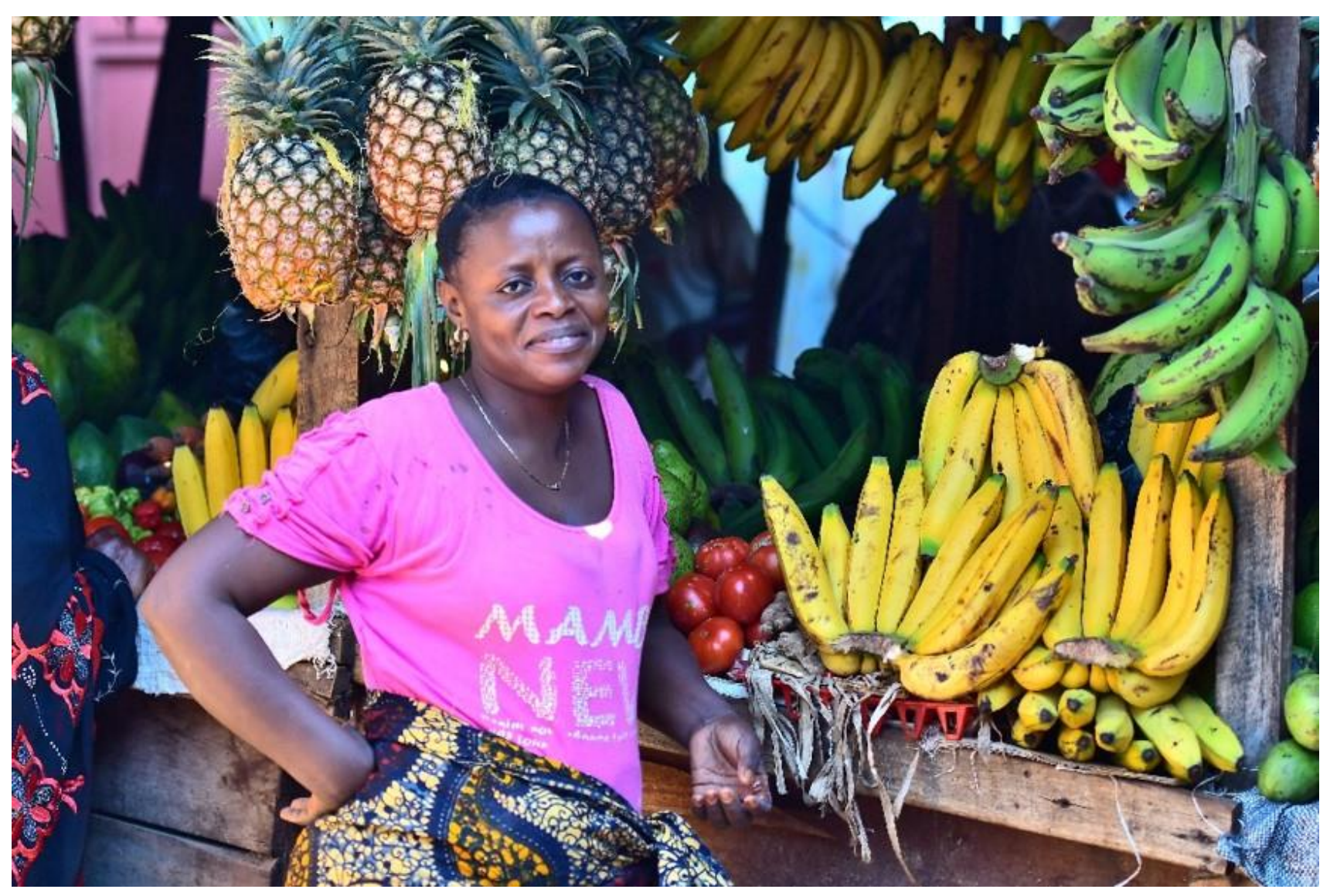

GAIN Convening Paper Series n³

August, 2019

Sarah Parkinson, Ashish Kumar Deo

gain 


\section{ABOUT GAIN}

The Global Alliance for Improved Nutrition (GAIN) is a Swiss-based foundation launched the UN in 2002 to tackle the human suffering caused by malnutrition. Working with governments, businesses and civil society, we aim to transform food systems so that they deliver more nutritious food for all people, especially the most vulnerable.

\section{Recommended citation}

Parkinson S, Deo A., Nourish our world [now]. Creating demand for nutritious diets. Global Alliance for Improved Nutrition (GAIN). Convening Paper Series 4. Geneva, Switzerland, 2019. DOI:

https://doi.org/10.36072/cp.4

\section{(C) The Global Alliance for Improved Nutrition (GAIN)}

The contribution of third parties do not necessarily represent the view or opinion of GAIN.

\section{Acknowledgements}

The authors wish to thank the NOW network of partners for their joint support in organising the workshop: Rod Connors and Colin Jenkinson, System 1 Agency; Sarah Swanson and Nathanial Peterson, Busara Centre Behavioural Economics; Yana Manyuk and Klaus Kraemer, Sight and Life; Justin Stokes, Ananda Partners; Siddharth Kanoria, Quantum Consumer Solutions and our colleagues at GAIN; Alison Tumilowicz, Alia Poonawala and Eva Monterrosa. Additional thanks to System 1 Agency for developing the visual identity for the NOW network and all the communications materials for the workshop. The authors also wish to thank Mieke Van Reenan, Marielle de Jonge and the entire GAIN Utrecht office for their support in identifying the venue and hotel for workshop and for all their help in preparation of the meeting. Special thanks go to consultant Marleen Menken for supporting the planning and logistics and to Wendy Gonzalez, Saul Morris and Lynnette Neufeld for reviewing an earlier version of this Convening paper. We also gratefully acknowledge the financial support of the Making Markets Work programme donors: Bill and Melinda Gates Foundation, the Government of the Federal Republic of German, International Development Research Council of Canada, Irish Aid, the Ministry of Foreign Affairs of the Netherlands, and the Swiss Agency for Development and Cooperation.

All photographs included in this document have been taken with consent for use in publications.

\section{GAIN CONVENING PAPER SERIES}

The GAIN Convening Paper Series brings together proceedings and reports from events that have been convened or co-convened by GAIN.

The Global Alliance for Improved Nutrition (GAIN)

Rue de Varembé 7

1002 Geneva

Switzerland

T: +41227491850

E: info@gainhealth.org

www.gainhealth.org

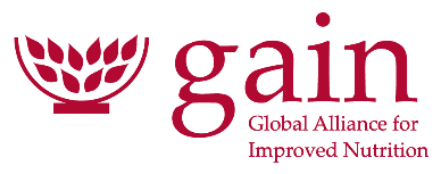



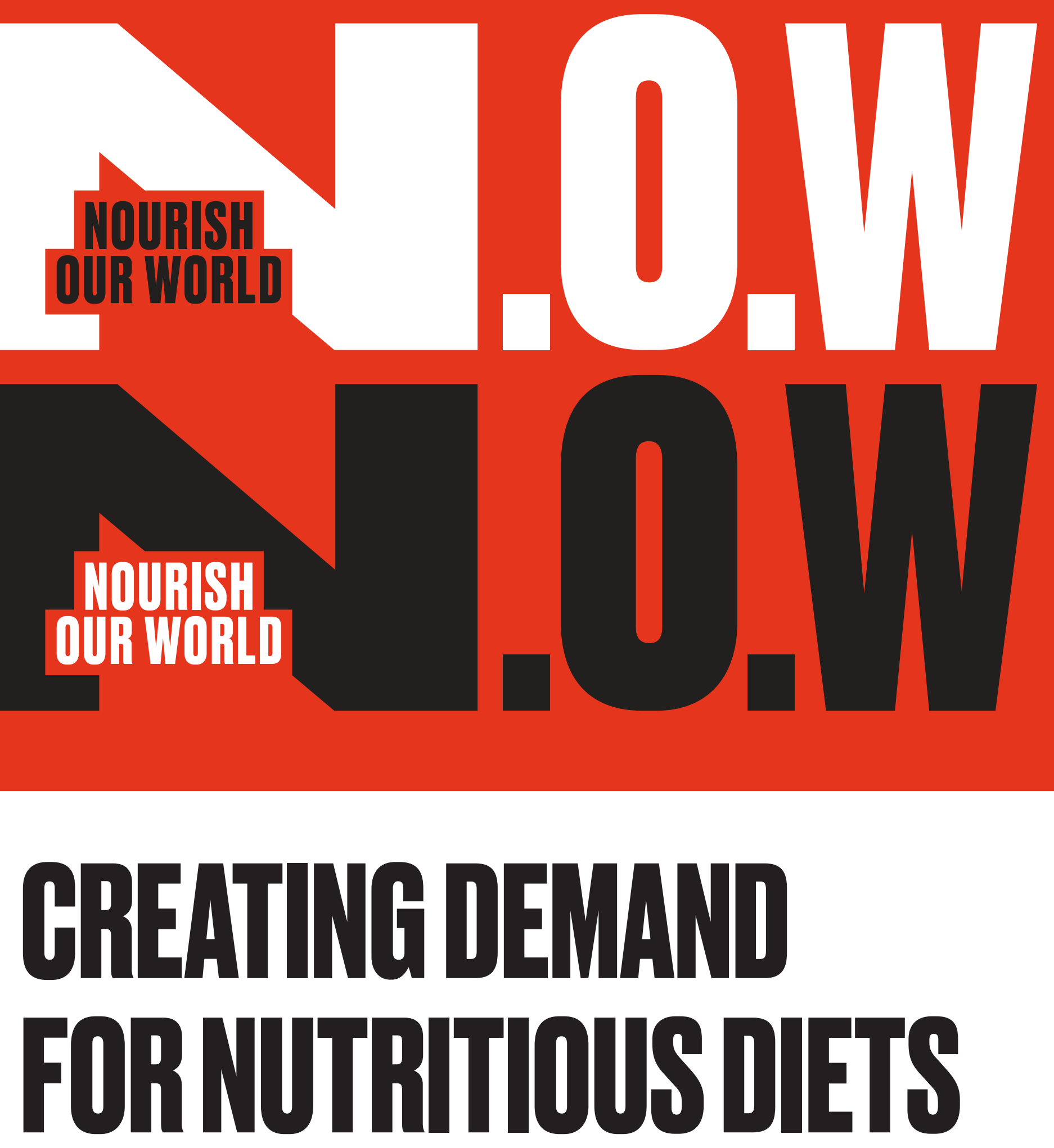

February 25-26,2019 Amsterdam, the Netherlands

Workshop Report 


\section{ABOUTNOW}

NOUR:BH OUR WORLD (NOW) seeks to put the power of demand creationat the core of improving the quality of diets indeveloping countries, especially among low-income consumers. This is becaulse a good quality diet is central to tacklingall forms of malnutrition.

OUR MiISSON is to increase testing, and at scale use, of demand creation strategles, be a plattform for best praetice, develop new sustainable business modeles for hetter quality foods and to generate funding streams for strategles that mobilize consumers around better quality diets.

NOW is a partnership devised by the Global Alliance for Improved Nutrition (GAIN) together with Ananda Partners, the Busara Center for Behavioral Economics, Quantum Consumer Solutions, Sight and Life, and System 1 Agency.

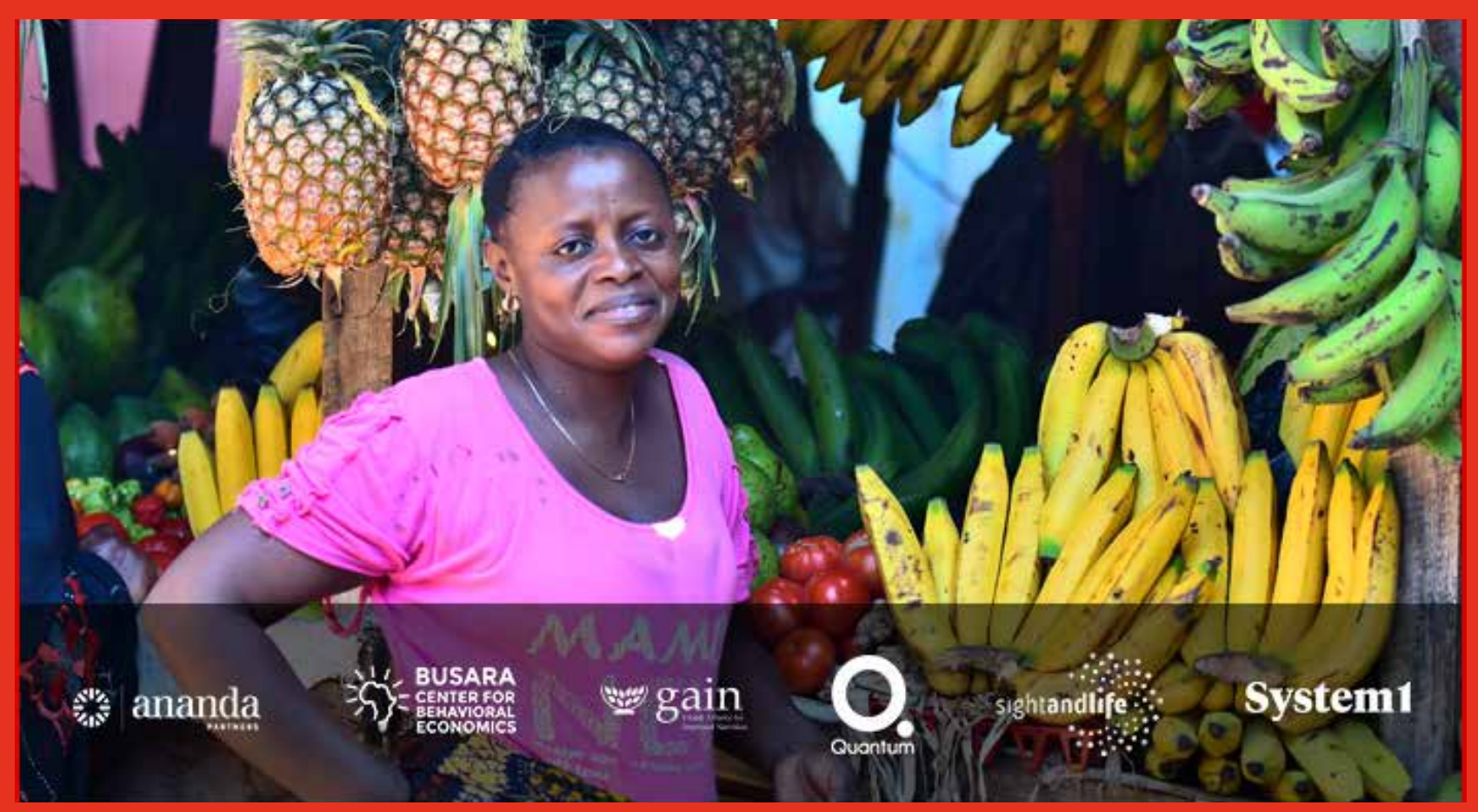




\section{THE GASEFORDEMAND GREATION}

Most people, including low-income households in developing countries buy much of their food from markets ${ }^{1}$. Therefore, it makes sense to treat them as consumers in a market setting. Our aim is to enable these consumers to improve their diets through the increasing consumption of nutritious and safe foods. This is because a good diet is central to tackling all forms of malnutrition.

Our approach recognises that in order to influence their food choices, these consumers need to see the benefits of an improved diet. We call this "demand creation". There are very few successful examples in the nutrition sector. Therefore, the organisations behind this workshop, NOW Amsterdam, have been working both independently and together with other organisations on programmes that are helping to improve our understanding of how to harness marketing to build demand.

GAIN examples include the Baduta programme that was launched in Indonesia in 2015-6, and new projects under the Making Markets Work programme in Nigeria, Bangladesh, Pakistan and Kenya. GAIN is designing and executing these projects in collaboration with the System 1 Agency, the Busara Center for Behavioral Economics, Ananda Partners and Quantum Consumer Solutions. Sight and Life examples include the Obaasima initiative in Ghana and 'Eat more, eat better'; social marketing research that uncovered the motivational drivers for healthy food choices during pregnancy and lactation in Rajasthan and Andhra Pradesh.

Despite this growing expertise, we know that there is considerable work happening beyond our group, and beyond our sector. As a response to this, the NOW network of partners co-hosted a workshop on demand creation for nutritious diets from February 25-26 2019 in Amsterdam, the Netherlands. The workshop was moderated by Professor V. Kasturi Rangan, Professor of Business Administration and Co-Chairman Social Enterprise Initiative at Harvard Business School; and Siddarth Kanoria, Partner for Quantum Consumer Solutions. It was attended by 30 experts from food related businesses, the development sector and academia, with representation from both high and low-income countries. The workshop aimed to understand:

1) How to make nutritious diets and foods desirable to consumers (tools, techniques, approaches)?

2) What sort of testing/experimentation is needed to develop and demonstrate scalable solutions?

3) What are the roles and responsibilities of businesses, donors and country governments in these efforts? 


\section{COMPONENTSOF SUCEESSFUL DEMAND GREATION}

Discussions were structured around three components of successful demand creation programmes:

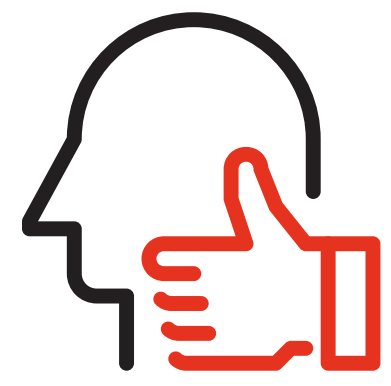

1) Motivating consumers to take action

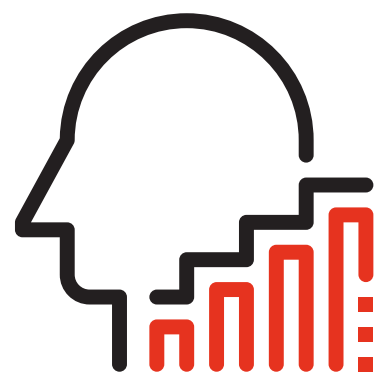

2) Business models for sustainable action

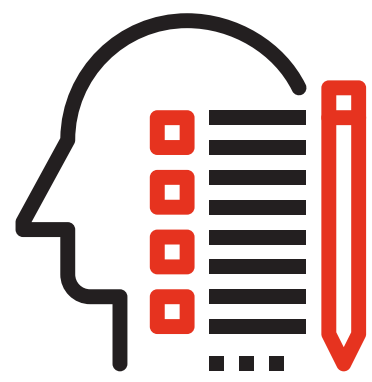

3) Policies and regulations to reinforce demand creation

Best-in-class examples of each of these components, from both nutrition and other sectors, were presented as stimulus for starting to solve some example challenges faced by the nutrition sector. 


\section{MOIILAILGGONSUMERS TOTAKEAGION}

\section{A champion's mother, a story from Rajasthan}

Pregnant and lactating women in Rajasthan, Northern India often eat least and last in their households, despite evidence and recommendations from community health workers that they should be eating more in quantity and more frequently. To address this, IPE partnered with Cartwheel to develop a communications campaign, rooted in an emotional insight to provoke behavioural change. The campaign identified a concern shared by everyone in the household, the health of an unborn child. This insight was then layered with emotional appeal in the campaign, Let's make the child a champion! Recognising the significance of men as potential supporters, bespoke advertising targeted the husband encouraging him to treat his wife as 'the Mother of a Champion'. The campaign aims to reach 1.06 million pregnant and lactating women, and has received a government commitment of USD 1.5 million per annum for mass media communications.

Raghwesh Ranjan, Director, Social and Economic Empowerment, IPE Global Limited, India, and Ramkrishna Desirajura, Director, Cartwheel Creative Consultancy

\section{MTV Shuga, a 360 degree model for behaviour change}

The MTV Staying Alive Foundation runs the MTV Shuga series; ground-breaking, original media content that delivers vital HIV and sexual and reproductive health messaging to a global audience. They use narrative storytelling in the form of scripted TV shows, through which young people can learn about and discuss public health ideas. The TV show is just the beginning of a 360 model of radio, social media and community-based discussion groups that allow viewers to fully explore the themes presented through the show's storylines.

Richard Warburton, Creative Director, MTV Staying Alive Foundation 


\section{MOTILATLNGGOKSUMERS TOTAKEAHION (onntinueri)}

\section{Motivating adolescents for social change in Bangladesh}

GAIN, in collaboration with Shornokishoree Network Foundation (SKNF), is designing a project for adolescents in Bangladesh to stimulate demand for better quality diets, and then deploy that demand to positively change the products developed by the food industry, and the policies and regulations developed by the government.

The starting point of the design process was the Adolescent Motivations Research completed by Quantum Consumer Solutions. This approach represents a new and innovative starting point. The study used ethnographic and qualitative methods to explore unstated, non-rational and compelling life insights and unearthed deeper life motivations. From these insights, a social movement is being developed by the adolescents of SKNF with support from Ananda Partners and Grey Bangladesh, which will culminate in the adolescents taking a pledge to spend their pocket money on better quality snack foods. In order to keep their pledge, they will meet with industry leaders and policy makers to gather support to improve the choices made available to them

Sarah Parkinson, Program Manager, Adolescent Nutrition (Consultant), GAIN, and Gousal Shaon, Managing Partner \& Country Head, Grey Bangladesh

\section{KEYTAKEAWAYS}

1. Motivating consumers means more than just encouraging them to take up new behaviours or use new products. As the theory behind the work in Bangladesh demonstrated, igniting consumer interest has the potential to provoke system level change.

2. Design for demand creation means establishing a new starting point for the consumer. Understanding what motivates them, and those who affect their decisions and understanding why and how they make decisions, allows for the emergence of behavioural, cultural and business insights that become the bedrock of value proposition development, campaign or product design.

3. Be where consumers are, and bring them ideas and information in ways that provoke them. MTV Shuga's model is built around a powerful piece of narrative storytelling that is underpinned by the equity of the MTV brand. Partnerships with brands and organisations with credibility are a key entry point to building consumer trust. 


\section{BUSINESSMODELSFOR} SUSTANABLEAGTION

\section{Testingand sealing impanthusiness models}

LivOpen is a mosquito repellent curtain with SmarTech technology, developed by Unilever and local partners in Indonesia. It provides comprehensive protection from mosquitos throughout the night and day. The product was born from a desire to address the needs of the 400 million people who are impacted every year by mosquito-born diseases. There are currently available solutions on the market, such as creams, sprays and coils, but they often provide disappointing results. Once the financial and operational models were built and the product blueprint designed, a process of validation, experimentation and iteration was carried out in-market. This involved four intense weeks of testing sales methods to overcome barriers to trial and determine the right level of service. Three key learnings resulted from this process: 1) build trust with your consumers, 2) de-risk the purchase decision, and 3) ensure an efficacious solution. Through this process, Unilever has designed a go-to-market model that has resulted in an $83 \%$ conversion rate from trial.

Clive Allison, Global Director for Innovation \& New Business Solutions, Unilever

\section{Selling financial produets to low ineome consumers}

ACRE is an insurance product, available to farmers in Kenya that protects them from weatherrelated poor harvests by giving them the chance to get their money back for the seeds they planted but had failed to grow. However, converting farmers to buy the product was proving challenging. Despite recognising the utility of the product, farmers weren't using it. This is common of many products where, despite the presence of demand, the follow-through to try, engage or stick with something is often lacking due to problems like motivation, attention or memory. This is especially true for products like insurance, where benefits can feel remote. To address this, the Busara team took a behavioural approach to demand generation and developed innovative ways to close the intention-action gap. For ACRE, this meant simple changes to the way the service was promoted to farmers when they purchased seeds, i.e. 1) relatable images to establish insurance as a social norm, 2) visuals of money to reinforce financial incentive, 3) images and copy that relayed insurance as the safe choice, and 4) visuals and images that showed that the process as simple and easy. The first approach, establishing insurance as a social norm resulted in a higher number of enrolments, and currently the product is using this messaging to attract new customers.

Sarah Swanson, Director, The Busara Center for Behavioral Economics 


\section{BUSINESSMODELSFOR SUSTAINABLE ACTION (continued)}

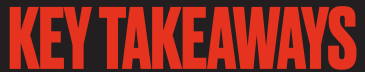

1. 'Business model' implies that a business is taking the lead and they are not just a supporter or enabler. The models developed should be 'coalition models' with multiple partners coming together to create a new entity to solve the problem. This means thinking differently from the outset by carrying out end-to-end value chain thinking to immerse the partners in the consumers' reality and determine the best way the coalition can operate to serve their need.

2. Business Model considerations need to be 'baked into' the value proposition itself to ensure the exercise results in real innovation.

3. Iterate, iterate, iterate. Whether that's designing the product, the go-to-market strategy or encouraging sales, business model solutions require constant iteration, innovation and management. 


\section{POLLEESANDREGULATIONS}

\section{The Chilean model: Boosting the effectiveness of promoting nutritious foods}

From 2009-2014, Chile had the greatest sales per capita/day from all sugar-sweetened beverages², the result of which was an epidemic of obesity and diet-related diseases. In 2016, Chile implemented the first set of marketing restrictions aimed to curb the consumption of products that are high in sugar, salt, saturated fat or calories. Packaged foods high in sugar, salt, saturated fat or calories are now required to carry a warning label on the front of pack. Those same companies are also restricted from advertising their foods at any point when more than $20 \%$ of the audience is less than 14 years old. In 2018, phase two of the regulations were rolled out, which included a total ban on advertising from 6am to $10 \mathrm{pm}$ for any product carrying a warning label, and a mandatory inclusion of the warning label on any advertising outside of those hours. While the evaluation is ongoing and data is not yet publicly available, the early signs indicate that the policies are working and many other countries are starting to explore these regulatory tools.

Barry Popkin, W. R. Kenan, Jr. Distinguished Professor, the Gillings School of Global Public Health, The University of North Carolina

\section{Leveraging cash transfers to improve nutrition worldwide}

Cash transfers, many of which are conditional, are a strategy to improve the purchasing power of low-income people. Preliminary findings from a literature review ${ }^{3}$ of 71 studies showed that $77 \%$ achieve significant improvements in dietary diversity, with around $80 \%$ of the transfer being spent on food. However, the same literature review found that programmes that include a component of behaviour change communication or education, are no more likely to achieve gains than are those that do not. What impact does the size of the transfer have; do programmes offering more achieve more? The transfer amount of successful programmes is USD 267/year, whereas unsuccessful programmes are USD 147/year, and the probability of heightening dietary diversity increases with the transfer amount. Taking this into consideration, there is still room and plenty of opportunity to utilise this strategy to support the purchasing power of participants in demand creation initiatives.

James Manley, Department of Economics, Townson University 


\section{POLGBESANDREEULATIONS (ontinued)}

\section{Obaasima, a demand driven approach to nutrition}

Obaasima is a symbol for fortified foods aiming to increase the availability of, and access to, affordable fortified foods in Ghana. The symbol guarantees nutritional quality making it easy for the target audience; women aged between 15-49, to identify fortified foods. The symbol aims to improve micronutrient intake in pregnant women and women of child-bearing age, to ensure that products have a sound nutrition profile and to increase the number of fortified food products, and access to healthy nutritious foods for women of reproductive age. Obassima works to generate demand for these products through branded (featuring partner products) and unbranded campaigns.

Daniel Amanquah, Food Scientist, Sight \& Life

\section{KEYTAKEAWAYS}

1. Policy change does not happen quickly but when it does deliver, for example the Chilean legislation, it has potential for far reaching impact.

2. The nature of many of the policies used in health and nutrition tend to focus on punitive policies to reduce food and drink that is unhealthy - so companies do less of what is bad for nutrition. Obaasima is an example of recognising that, with support, national manufacturers can be part of the solution and as such they can also be incentivized to do more of what is good for nutrition.

3. Demand creation inherently is encouraging consumers to make better choices, whereas policy often works for preventing poor choices. Synergies may exist between these two goals, but they need to be fostered, developed, and tested. 


\section{HOWTHESEGOMPONENTS FITTOGETHER}

Demand creation is a non-linear, systems equation in which neither consumers, the food industry nor the regulatory environment can work in isolation. They have the potential, if activated - through collaborative models centred around a problem with both scale and high potential - to be able to reinforce one another for mutual gain. However, systems are complex and it's very hard to see the most effective lever to pull at what time. The reality, as other systems interventions have demonstrated, is that we will not. There are too many feedback loops that cannot be accounted for in design.

We need to activate each area; igniting consumer agency, designing the policy environment and building the business case for change. From here, it's possible to understand which levers work and how to improve on those that do not. From this workshop, key learnings have emerged about how to build for the constituent parts of policy, consumer and industry. The next steps for the NOW network will be bringing these learnings to bear on a single problem, in a single geographic location, to therefore build a solution that reflects the mutually reinforcing capability of these tools.

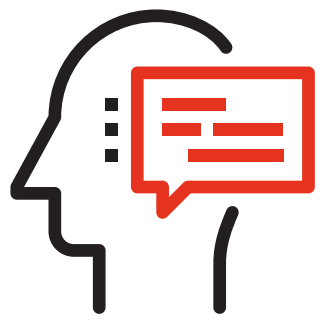

\section{REEULLATORY}

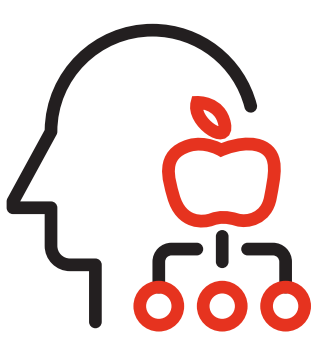
ENVIRONMENT Drivers

- Government capacity

- Political climate

- Socio-economic conditions FOOD INDUSTRY

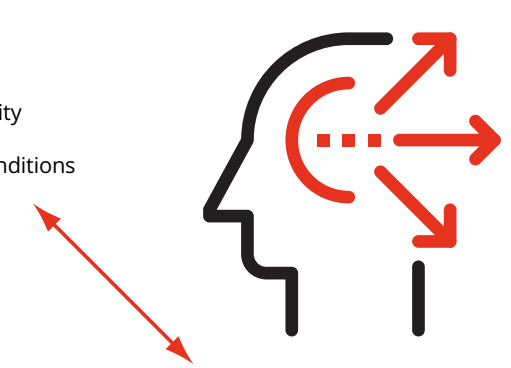

Drivers

CONSUMERAGENGY

- Market size + structure

- Competition/market dynamics

- Supply chain structure

- Access and application of technology

- Unit economics

Drivers

- Desire/Motivation/Identity

Awareness

Awareness

Consumer Value Proposition

Engagement + interaction

- Advocacy 


\section{SUMMARY}

There are many reasons to be optimistic

- There is a huge market for quality foods and previous examples that prove business does respond when the opportunity is clear.

- The workshop was a collaboration of business, policy and consumer behaviour demonstrating a clear desire to work together to develop solutions.

- As evidence becomes available, momentum gathers. The recent policy work in Chile is beginning to show that it is possible to shape the market. Many more countries are watching for the release of those findings.

- Of the many collaborations that already exist, learnings from this workshop show that they all have potential to be more effective.

We must take a systems view

- A dynamic group makes systems interactions much easier to see but it's very difficult to know which lever in a system, or combination of levers has the most impact. The reality, as other systems interventions have demonstrated, is that we won't. There are too many feedback loops that cannot be accounted for in design.

- A system needs a test market, to be able to intervene in different ways, testing different levers and measuring to see where the impact is achieved.

We must have patience

- Shifting markets is a long-term endeavour and it's important to note that realistic timelines are established.

- There will undoubtedly be trade-offs all along the way, so setting realistic expectations will be key.

- There is a great sense of urgency to act but the complexity of the systems we're designing for mean that we need to carefully craft the agenda and allow the time to give emerging ideas meaningful shape.

\section{Connect the dots}

- NOW has created a platform for collaboration on these problems and demonstrated that we are in the best position when we work together. Working together, with our combined expertise, in a single geography, will allow the required focus and evidence. 


\section{APPENDICIES}

\section{APPENDIX1:REFERENGES}

1. HLPE. 2017. Nutrition and food systems. A report by the High Level Panel of Experts on Food Security and Nutrition of the Committee on World Food Security, Rome

2. Popkin \& Hawkes, Lancet Endocrinoloy, 2015.

3. Unpublished literature review of 71 cash transfer programmes. 

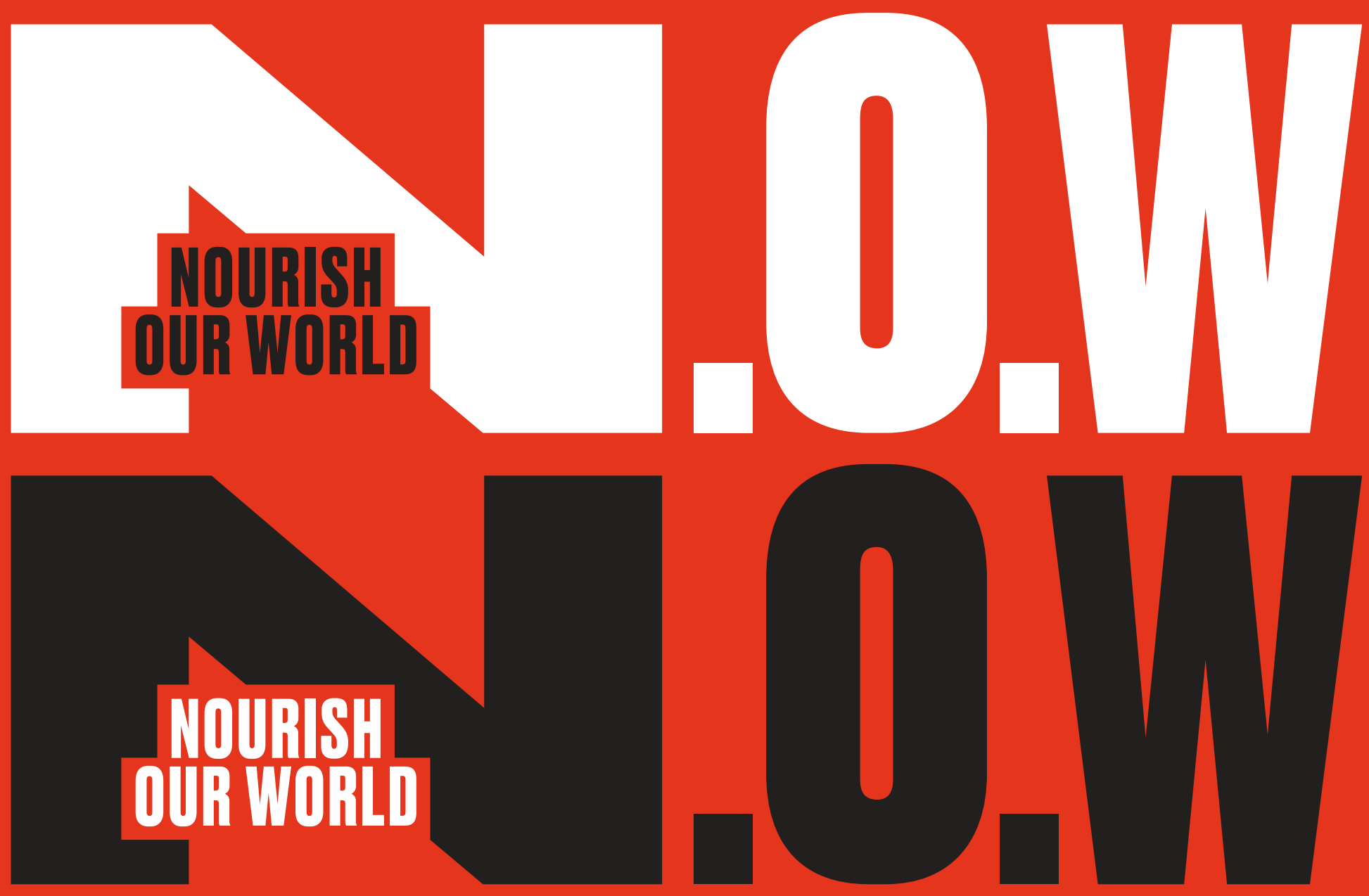

彭 ananda

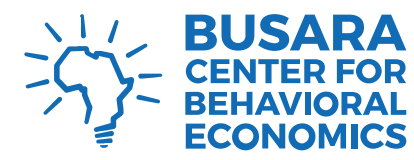

gaing

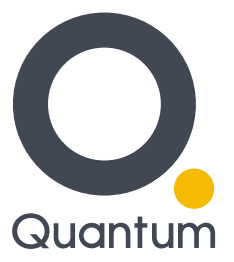

sightandlife $\because \because$

System1 